\title{
Histological and Biochemical Study on the Possible Protective Effect of Nebivolol on Gentamicin Induced Nephrotoxicity in Adult Male Albino Rats
}

\author{
Original \\ Article \\ Shereen Tawfeek ${ }^{1,2}$ and Lamya Ali ${ }^{1,3}$ \\ ${ }^{1}$ Department of Anatomy, College of Medicines, Jouf University, Saudi Arabia \\ Department of Human Anatomy and Embryology, Faculty of Medicine, ${ }^{2}$ Zagazig University, \\ ${ }^{3}$ Beni suef University, Egypt
}

\begin{abstract}
Background: Gentamicin is a powerful aminoglycoside antibiotic which is widely used in the proper eradication of gramnegative organisms. Acute renal failure is a common complication that develops rapidly through a dose-dependent mechanism after gentamicin administration. Nebivolol is a third generation vasodilator selective $\beta-1$ adrenergic receptor blocker which has a potent antioxidant properties that that could ameliorate the renal adverse effects which could be exerted by gentamicin administration.

The Aim of work: Is to elucidate the protective effect of nebivolol in gentamicin induced nephrotoxicity.

Material and Method: Thirty adult male albino rats weighing 180-220 gm were used in this study. The rats were divided into three groups( 10 rats each for each group): Group I (control group). Group II (Gentamicin treated group). Group III (Gentamicin and nebivolol treated group). The total duration of the experiment was 30 days (one month). Rats of all groups were anaesthetized then the rats were sacrified at day 31(the day after the end of experiment).

Results: The administration of gentamicin resulted in shrinkage of the glomeruli, there were widened urinary space and also most of proximal and distal convoluted tubules presented pyknotic and karyolitic nuclei, there was extensive cytoplasmic vacuolation,there were a significant elevation of blood urea nitrogen ,a significant elevation of creatinine levels and metalloproteinase matrix 9 (MMP 9) which were improved markedly by administration of nebivolol drug.

Conclusion: It could be concluded that nebivolol may improve the adverse histological and functional changes induced by gentamicin in the adult male albino rat's kidney.
\end{abstract}

Received: 12 February 2020, Accepted: 11 April 2020

Key Words: Gentamicin, kidney, nebivolol.

Corresponding Author: Lamya Ali Abd El Salam, MD, Department of Anatomy, College of Medicine, Jouf University, Saudi Arabia. Department of Anatomy and Embryology, Faculty of Medicine, Beni Suef University, Egypt, Tel.: +966 545387403, E-mail: laabdalla@ju.edu.sa

ISSN: 1110-0559, Vol. 44, No.1

\section{INTRODUCTION}

Gentamicin is effective aminoglycoside antibiotic commonly used in proper gram-negative organism eradication. Acute renal failure is a common complication that progresses rapidly through a dose-dependent mechanism after administration of gentamicin. This drug is excreted in the urine and after discontinuation of the drug, several particles remain in the renal cortex for a long time. Through glomerular filtration, gentamicin is removed and partly reabsorbed through proximal tubular cells. The drug's nephrotoxicity is due to its selective accumulation in the proximal tubules of the kidney, reaching a higher plasma concentration than that of the renal tubules. Gentamicin administration results in rapid and pronounced necrosis of renal tubular cells and increased levels of plasma creatinine and blood urea nitrogen, resulting in acute kidney injury and renal failure. Measuring the plasma level of gentamicin in hospitalized patients, particularly in paediatric patients, is therefore mandatory after the third dose ${ }^{[1,2,3,4,5]}$. Gentamicin induced inflammatory reaction is mediated through decreased release of endothelial nitric oxide and increased production of reactive oxygen species (ROS) that exert peroxidation of membrane lipids and DNA injury. The most serious ROS is inducible nitric oxide that is much increased by gentamicin administration resulting in initiation of a serious apoptotic pathway of renal tubular cells $s^{[6,7]}$. Nebivolol is a third generation vasodilator selective $\beta-1$ adrenergic receptor blocker currently used in management of cardiovascular diseases. The vasodilator criteria can be attributed to release of endothelial nitric oxide via a $\beta 3$-adrenoceptor. Nebivolol has powerful antioxidant properties. Treatment with this vasodilator increases renal tissue levels of bioavailable nitric oxide and reduces renal inflammation and cell necrosis ${ }^{[8,9,10,11,12]}$. 


\section{MATERIALS AND METHODS}

\section{Chemicals}

1. Nebivolol (NBV): was purchased from Marcyryl Pharmaceutical Industries, Egypt. NBV powder diluted with saline and given orally by nasogastric gavage at a dose of $8 \mathrm{mg} / \mathrm{kg}$ once daily ${ }^{[5]}$ for 30 days in group III.

2. Gentamicin (GEN): was purchased from MISR pharmaceutical company, Egypt. The powder was dissolved in saline and injected intraperitoneally at a dose of $80 \mathrm{mg} / \mathrm{kg}$ once daily in the last seven days in group II and first 7 days in group III[ ${ }^{[5]}$.

\section{Animals}

Adult male albino rats (thirty in number), their average weight was $170-250 \mathrm{~g}$. The animals obtained from the animal house, Faculty of Medicine, Cairo University.

\section{Experimental Design}

The rats were maintained under balanced environmental and laboratory conditions, fed with standard diet and they were housed in separate cages for each animal, the duration of the experiment was 30 days. The rats were divided into three groups 10 rats each:

Group I (control): The rats of this group were intraperitoneally injected with $0.9 \% \mathrm{NaCl}$ once daily for 30 days.

Group II (Gentamicin administration): The rats of this group were intraperitoneally injected with $0.9 \% \mathrm{NaCl}$ once daily for 23 days (from day 1 to day 23) followed by intraperitoneal injection with gentamicin at a dose of $80 \mathrm{mg} /$ $\mathrm{kg}$ once daily for the following seven days (from day 24 to day 30 )

Group III (Gentamicin and nebivolol administration): The rats of this group were intraperitoneally injected with gentamicin dissolved in saline at a dose of $80 \mathrm{mg} / \mathrm{kg}$ once daily for seven days (from day 1 to day 7) with oral administration of nebivolol (by gastric gavage) at a dose of $8 \mathrm{mg} / \mathrm{kg}$ once daily (from day 1 to day 30 ).

At the end of the experiment (at day 31), blood samples were obtained for assessment of biochemical markers of kidney from all groups then the rats from all groups given deep anaesthesia and sacrificed. The animals in different groups were handled carefully according to guidelines approved by the animal ethical committee of Cairo University ${ }^{[13]}$.

\section{Methods}

\section{1-Serum preparation}

Under isoflurane anaesthesia, blood samples were collected, under complete aseptic conditions, from the rat retro-orbital venous plexus by means of micro-capillary glass tubes. Blood was allowed to coagulate at room temperature, then by using a cooling centrifuge (Sigma 3-30 k, USA), then for 20 min the samples were centrifuged at $4000 \mathrm{rpm}$. The clear serum layer was separated and stored at $-80 \circ \mathrm{C}$.Biomarkers \{Blood urea nitrogen (BUN) and serum creatinine concentrations $(\mathrm{SCr})\}$ were measured spectrophotometrically ${ }^{[14,15]}$.

\section{2-Histological Study}

Rats of all groups were anaesthetized with sodium thiopental $75 \mathrm{mg} / \mathrm{kg}$ intraperitoneal ${ }^{[13]}$. kidney specimens were carefully dissected, excised and parts of it prepared for Histological study. Other parts were dissected then washed with saline (ice-cold) after that, in liquid nitrogen $\left(-170^{\circ} \mathrm{C}\right)$, the specimens were frozen then they were kept at $80^{\circ} \mathrm{C}$ for detection of matrix metalloproteinase-9 (MMP-9)

\section{a-Light Histological Study}

Preparation of paraffin sections ${ }^{[16]}$ : Impregnation of kidney specimens in molten paraffin wax in an automatic processor was done. Blocks of paraffin were formulated. By the rotary microtome,these blocks were sectioned at 4-5 microns. On glass slides the sections of samples were collected, then the sections were deparaffinized, after that they stained by Hematoxylin and Eosin to show the general structure of the tissue. By the light electric microscope (LEICA ICC50 W), slides were examined, this was done at Faculty of Agriculture, Cairo University.

\section{b- Electron microscopic examination ${ }^{[17]}$}

After sacrifaction of the animals, small kidney specimens $(10-12 \mathrm{~mm})$ were washed in a buffer of phosphate ( $\mathrm{pH}$ 7.2-7.4) for $25 \mathrm{~min}$ up to four times after they were already fixed in $5 \%$ gluteraldehyde for one day.The specimens then were post fixed for $2 \mathrm{~h}$ in osmium tetroxide (1\%). Then the specimens washed in a similar buffer for 25 min for five times each. Then by using gradual ascending grades of alcohol concentration $(30,50,70,90$, and absolute alcohol) each last for $2 \mathrm{~h}$, dehydration was carried out. Then by using gelatin capsule, they were embedded in Epon 812 ,after they were already cleared in propylene oxide. The samples then were put in an incubator at $35^{\circ} \mathrm{C}$ for 24 hours, then at $45^{\circ} \mathrm{C}$ for another 24 hours, and finally at $60^{\circ} \mathrm{C}$ for 72 hours . Semithin section (about 0.5-1 $\mu \mathrm{m}$ ) are cut with the ultramicotome and attained with toluidine blue to be examined by light microscope to choose the area for ultrathin sections. On copper grids, ultrathin sections $(50-100 \mathrm{~nm})$ were collected from the selected areas of trimmed blocks. Then in uranyle acetate ,for about $10 \mathrm{~min}$, the ultrathin sections were contrasted and in lead citrate for $5 \mathrm{~min}$. Then by using a transmission electron microscope (JEOL JEM-1200 EX II, Japan), the grids were subjected for examination and photographing .The microscope operated at $60-70 \mathrm{kV}$, This was done at (Electron Microscope Unit), pathology department, National Cancer Institute (NCI).

\section{3-Real-time quantitative reverse-transcription polymerase chain reaction ( $q R T-P C R)$ for mmp-9 ${ }^{[18]}$}

Using SV Total RNA Isolation System (Promega, Madison, WI, USA) total RNA was extracted from frozen kidney and then by using spectrophotometer they 
were quantified at $260 / 280 \mathrm{~nm}$. Then by incubating Rnase-free DNase I with RNA, the residual genomic DNA was removed. By using RTPCR kit (Stratagene, USA), the total extracted RNA was reversetranscribed into complementary DNA (cDNA) . For reverse transcription of RNA, random hexamers (primers) for MMP-9 (GenBank accession number NM_009660.3 gene was used. Using Forward primer: 50 -CACAGACAGCCTTCTGCAAC-30, reverse primer: 50 -CATTTCCCACAGCCTTGAAT-30 in $60^{\circ} \mathrm{C}$, product size $141 \mathrm{bp}$. By using the comparative (2DDCt) method relative changes in gene expression levels of samples to control were determined ${ }^{[19]}$.

RESULTS

\section{Results of Histological Studies}

Group I (control) Light microscopic examination of the renal cortex stained with haematoxylin and eosin (Hx\&E) presented renal corpuscles, formed of a dense rounded glomerulus surrounded by a parietal layer of Bowman's capsule with the urinary space in-between. The lining cells of proximal convoluted tubules were low columnar and the cytoplasm was strongly acidophilic with spherical basal nuclei. The lining cells of distal convoluted tubules were low cuboidal with acidophilic (faint) cytoplasm and rounded central nuclei (Figure 1). Electron microscopic examination of proximal convoluted tubular cells displayed rounded heterochtomatic nucleus with prominent nucleolus and intact nuclear envelop, intact apical microvilli, plentiful mitochondria (electron dense and parallel) are located between the basal cell membrane and the nucleus. Intact basal infoldings could be observed (Figures 2,3).

Group II (Gentamicin administration): Light microscopic examination of the renal cortex stained with (Hx\&E) presented extremely shrunken glomeruli with a widened urinary space (Figure 4). Most of proximal and distal convoluted tubules presented pyknotic and karyolitic nuclei with extensive cytoplasmic vacuolation epithelial, intraluminal casts and epithelial cell exfoliation (Figures 4,5) .Mononuclear cell infiltration and hyaline degeneration could be seen (Figures 6,7). Extravasated blood was also noticed (Figures 5,7). Electron microscopic examination of proximal convoluted tubular cells showing the cells of proximal convoluted tubules with transversely cut microvilli (Figure 8).

Group III (Gentamicin and nebivolol administration): Light microscopic examination of the renal cortex stained with (Hx\&E) showed a rounded glomerulus surrounded by a parietal layer of Bowman's capsule with the urinary space in-between. Proximal and distal convoluted tubules were more or less normal( apparently). Few tubules exhibit karyolitic nuclei with cytoplasmic vacuolations and an extremely shrunken glomerulus with a widened urinary space (Figures 9,10). Electron microscopic examination of proximal convoluted tubular cells displayed rounded heterochtomatic nucleus with more or less intact nuclear envelop, The mitochondria (parallel and electron dense) located between the thin basal cell membrane and the nucleus. Intact basal infoldings. Few cells presented indented nuclear envelop. (Figures 11, 12, 13, 14, 15).

4- Statistical analysis of data: Using SPSS software statistical computer package version 22 (SPSS Inc, USA), the collected data were organized, tabulated and statistically analyzed.The mean and standard deviation were calculated. to test the difference between mean values of measured parameters among groups, ANOVA (Analysis of variance) was used. By using Tukey HSD (Post hoc range test), multiple comparison between pairs of groups were done. For analysis of results of tests of significance, $P \leq 0.05$ was considered significant.

BUN (Blood urea nitrogen) was statistically significantly higher in group II $(76.65 \pm 9.96)$ and III $(33.48 \pm 4.79)$ compared to control $(19.18 \pm 3.76), p<0.0001$ and 0.015 , respectively. Also, there was a statistically significant difference between group II and group III $(p<0.0001)$ (Table 1, Histogram 1).

Serum creatinine was statistically significantly higher in group II (5.37 \pm 1.53$)$ compared to control $(1.01 \pm 0.14)$, and group III $(1.95 \pm 0.63), p<0.0001$. However, there was no statistically significant difference between group I and group III ( $\mathrm{p}=0.301)$ (Table 2, Histogram 2).

MMP 9 was statistically significantly higher in group II $(2.11 \pm 0.53)$ compared to control $(0.25 \pm 0.10)$, and group III $(0.88 \pm 0.09), p<0.0001$. Also, there was a statistically significant difference between group I and group III $(\mathrm{p}=0.020)($ Table 3, Histogram 3).

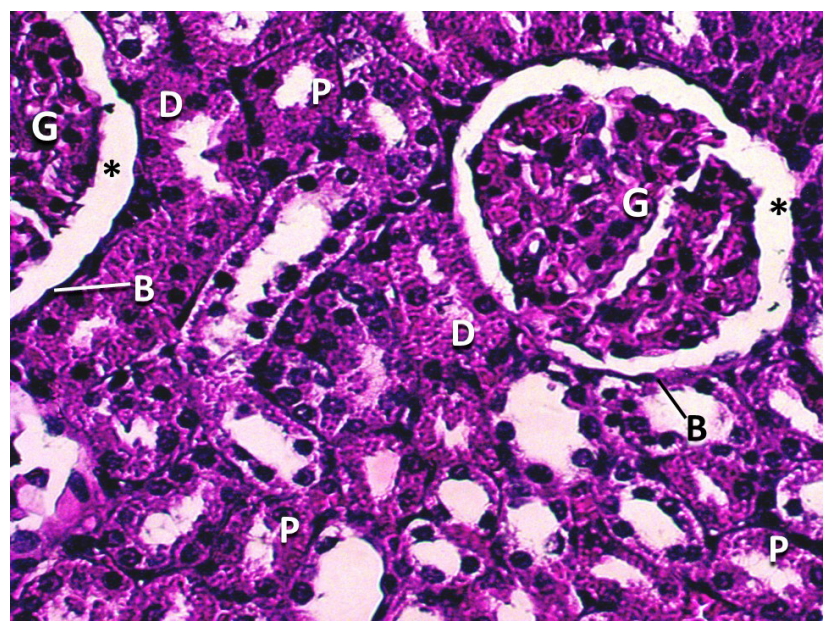

Fig. 1: A photomicrograph of a cross section of the renal cortex of a rat of group I (Normal control) showing renal corpuscles, formed of a dense rounded glomerulus $(G)$ surrounded by a parietal layer of Bowman's capsule (B) with the urinary space (*) in-between. The lining cells of proximal convoluted tubules $(\mathrm{P})$ are low columnar with spherical basal nuclei and strong acidophilic cytoplasm. The lining cells of the distal convoluted tubules (D) are low cuboidal with central rounded nuclei and faint acidophilic cytoplasm. (Hx\&EX400). 


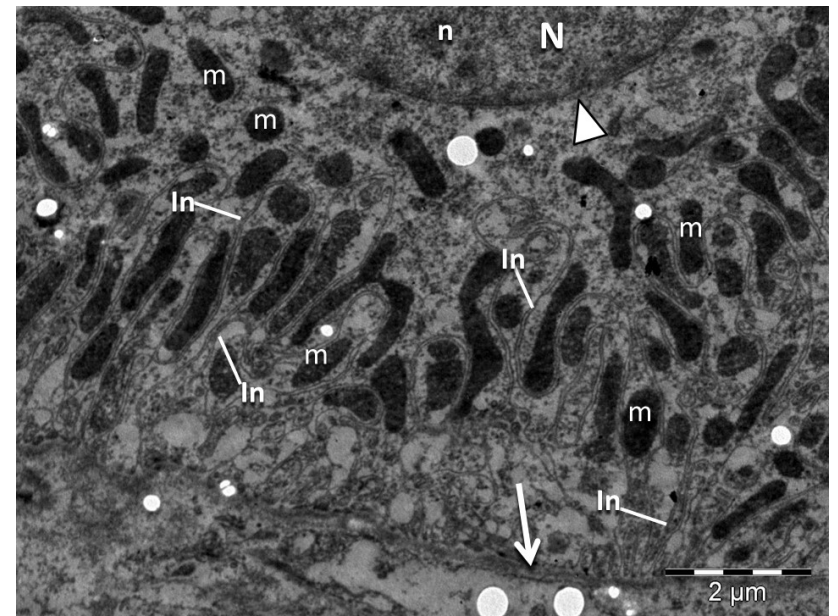

Fig. 2: An electron micrograph of a rat kidney of group I (Normal Control) showing the cells of proximal convoluted tubules with heterochtomatic rounded nucleus $(\mathrm{N})$ with intact nuclear envelop (arrowhead) and prominent nucleolus (n), plentiful electron dense parallel mitochondria $(\mathrm{m})$ are located between the nucleus and a basal cell membrane which is uniformly thin (thin arrow). Intact basal infoldings (In) can also be noticed (EMX 7100).

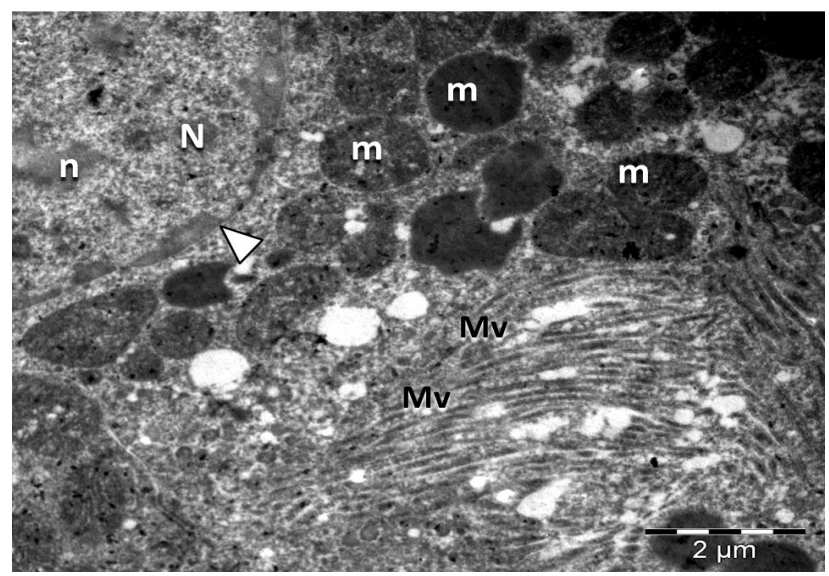

Fig. 3: An electron micrograph of a rat kidney of group I showing the cells of the proximal convoluted tubules with heterochtomatic rounded nucleus (N) with intact nuclear envelop (arrowhead) and prominent nucleolus (n), plentiful electron dense parallel mitochondria $(\mathrm{m})$ and intact microvilli (Mv) (EMX 89000).

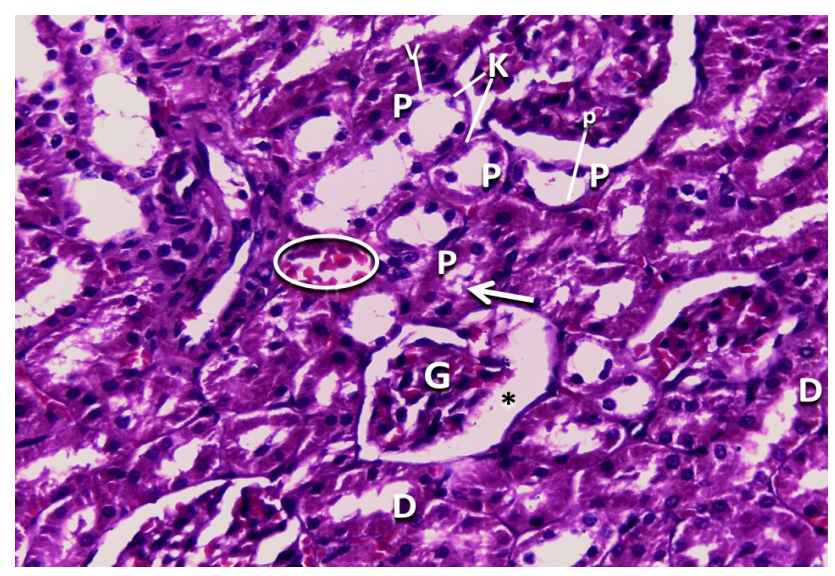

Fig. 4: A photomicrograph of a cross section of the renal cortex of a rat of group II (Gentamicin administration group) showing extravasated blood (Circle), extremely shrunken glomeruli $(G)$ with an abnormally wide urinary space (*). Most of proximal convoluted tubules $(\mathrm{P})$ present pyknotic(p) and karyolitic (K) nuclei with cytoplasmic vacuolations (v). Apparently normal distal convoluted tubules(D) can also be noticed (H \&E.X 400).

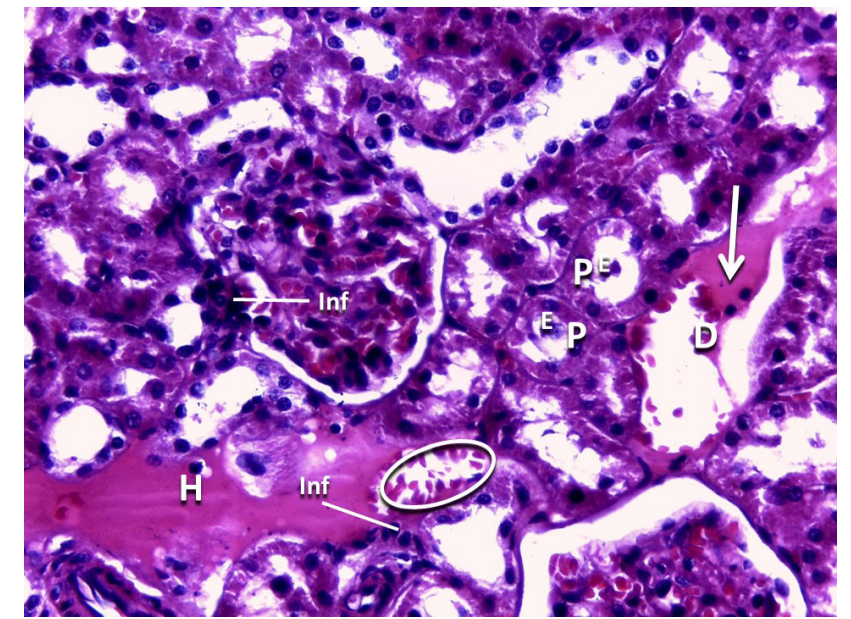

Fig. 5: A photomicrograph of a cross section of the renal cortex of a rat of group II showing extravasated blood (Circle), mononuclear cell infiltration (Inf) and hyaline degeneration $(\mathrm{H})$. Most of proximal $(\mathrm{P})$ convoluted tubules present exfoliated (E) lining epithelium. A distal (D) convoluted tubule contain cast with exfoliated cells (arrow) (H\&EX 400).

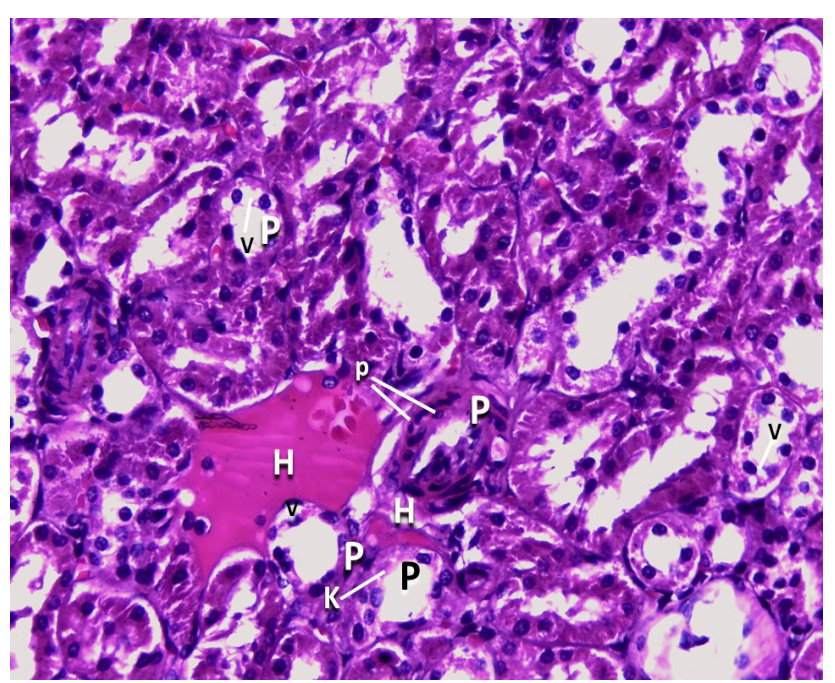

Fig. 6: A photomicrograph of a cross section of the renal cortex of a rat of group II showing hyaline degeneration $(\mathrm{H})$. Most of proximal $(\mathrm{P})$ convoluted tubules present pyknotic $(\mathrm{p})$ and karyolitic $(\mathrm{K})$ nuclei with cytoplasmic vacuolations (v). (H\&EX 400)

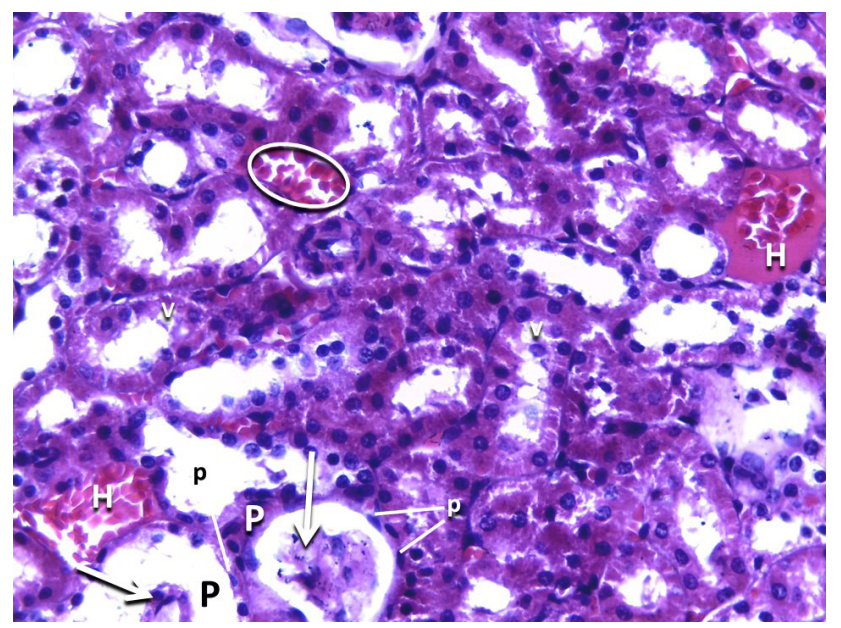

Fig. 7: A photomicrograph of a cross section of the renal cortex of a rat of group II showing extravasated blood (Circle), hyaline degeneration $(\mathrm{H})$. Proximal $(\mathrm{P})$ convoluted tubules present pyknotic (p) nuclei with cytoplasmic vacuolations (v). (Hx.\&E.X 400). 


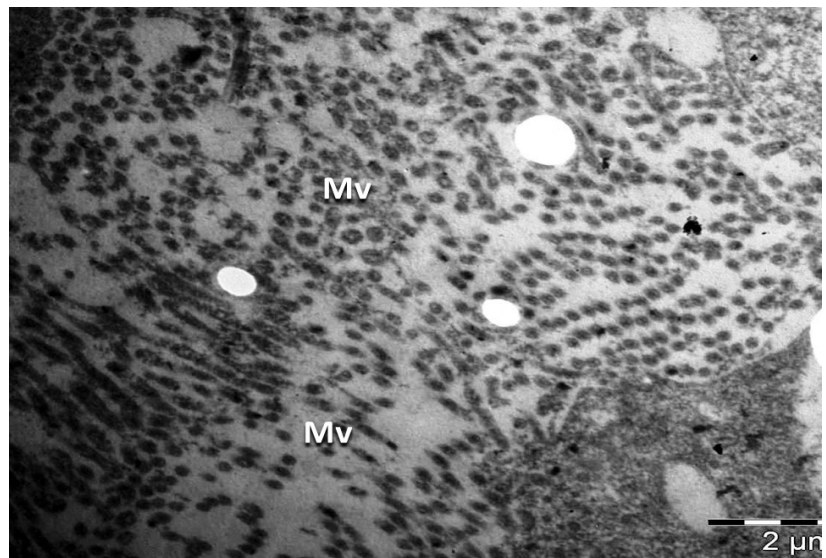

Fig. 8: An electron micrograph of a rat kidney of group II showing the cells of proximal convoluted tubules with transversely cut microvilli (Mv) (EM $\mathrm{X}$ 14000).

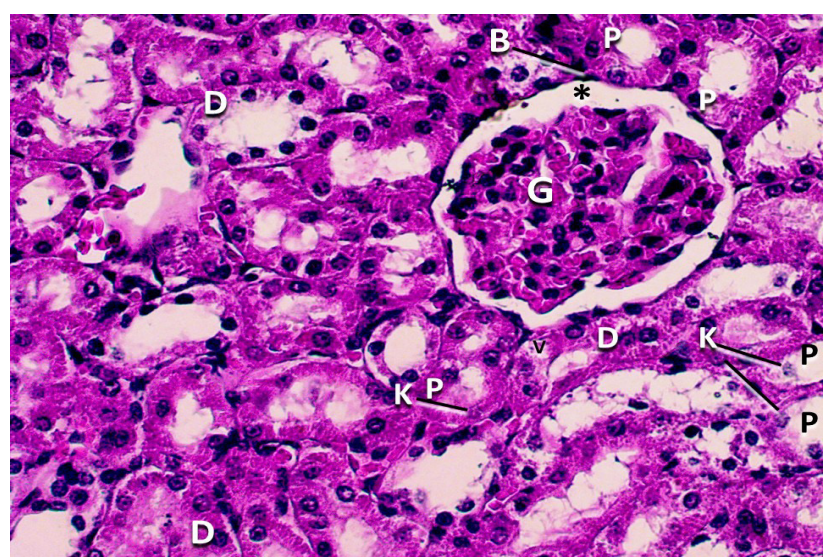

Fig. 9: A photomicrograph of a cross section of the renal cortex of a rat of group III (Gentamicin and nebivolol adminstration group) showing more or less normal proximal convoluted tubules $(\mathrm{P})$ and distal convoluted tubules (D), renal corpuscles, apparently normal and formed of a rounded dense glomerulus (G) surrounded by a parietal layer of Bowman's capsule (B) with more or less normal urinary space $(*)$ in-between. Few tubules exhibit karyolitic (K) nuclei with cytoplasmic vacuolations (v) canbeobserved (Hx.\&E.X400)

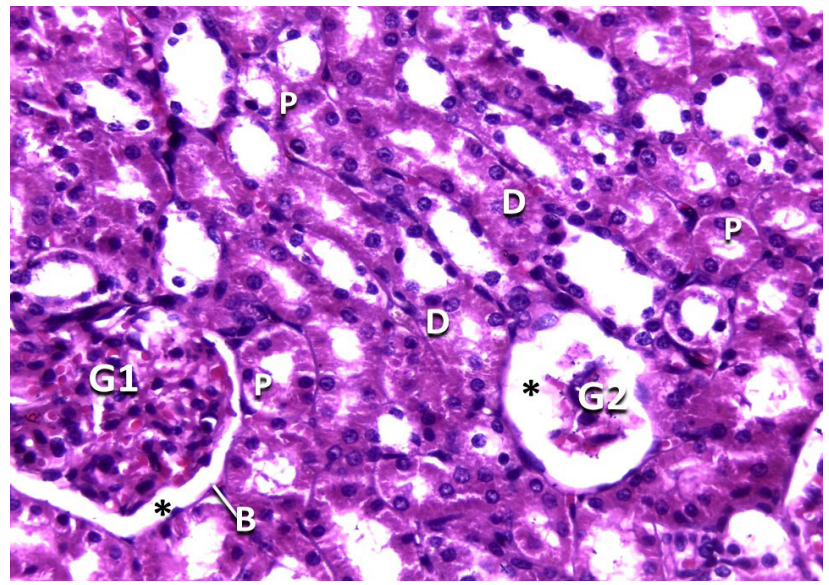

Fig. 10: A photomicrograph of a cross section of the renal cortex of a rat of group III showing: renal corpuscles, formed of a rounded dense glomerulus (G1) surrounded by a parietal layer of Bowman's capsule (B) with more or less normal urinary space $(*)$ in-between. An extremely shrunken glomerulus (G2) with an abnormally wide urinary space $(*)$ inbetween. More or less normal proximal convoluted tubules (P) and distal (D) convoluted tubules can also be noticed (Hx.\&E.X400).

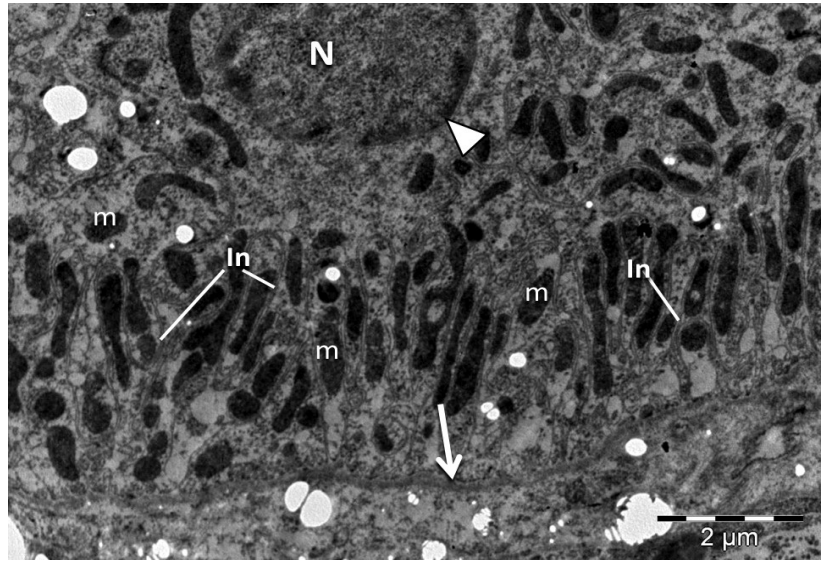

Fig. 11: An electron micrograph of a rat kidney of group III showing the cells of proximal convoluted tubules with heterochtomatic rounded nucleus (N) with more or less normal nuclear envelop (arrowhead), plentiful electron dense parallel mitochondria $(\mathrm{m})$ are located between the nucleus and the apparently thin basal cell membrane (thin arrow). Intact basal infoldings (In) can also be noticed. (EM X 5600).

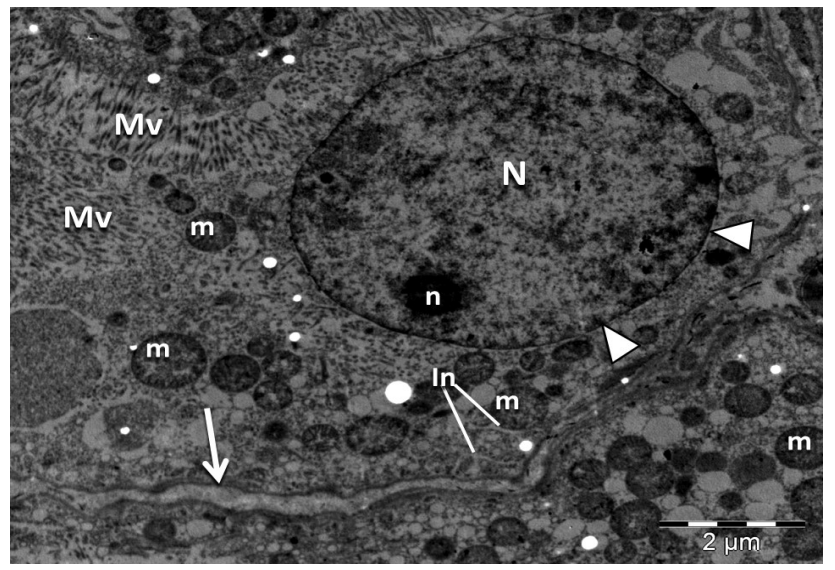

Fig. 12: An electron micrograph of a rat kidney of group III showing the cells of proximal convoluted tubules with heterochtomatic rounded nucleus $(\mathrm{N})$ with prominent nucleolus (n) and apparently normal nuclear envelop (arrowhead), scattered electron dense parallel mitochondria (m) are located between the nucleus and a uniformly thin basal cell membrane (thin arrow). basal infoldings (In) transversely cut microvilli (Mv) can be noticed. (EM $\mathrm{X} 4400)$.

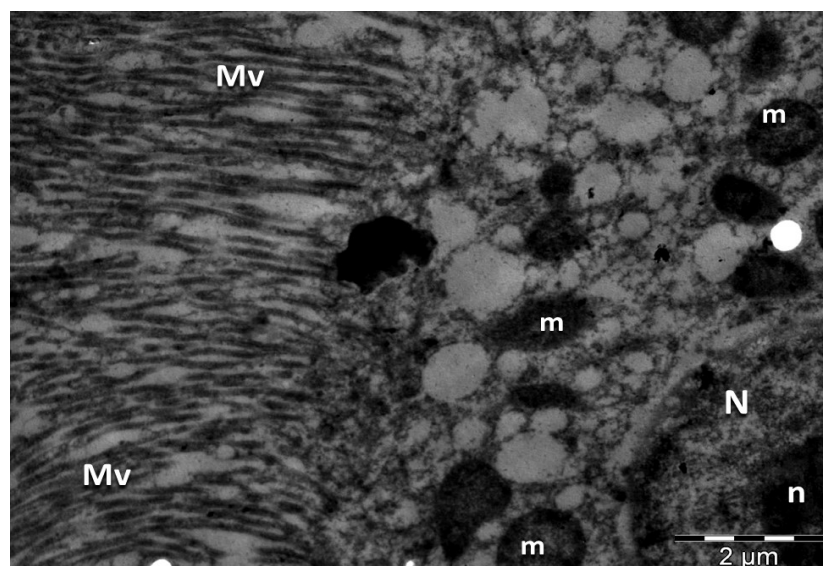

Fig. 13: An electron micrograph of a rat kidney of group III showing the cells of proximal convoluted tubules with heterochtomatic rounded nucleus $(\mathrm{N})$ with a prominent nucleolus (n), scattered electron dense parallel mitochondria (m) and apparently normal apical microvilli (Mv). (EM X 11000). 


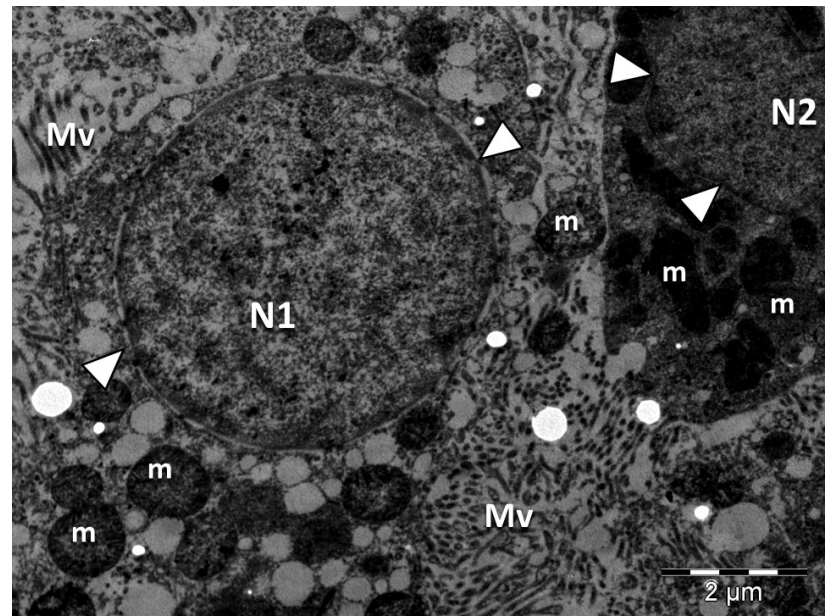

Fig. 14: An electron micrograph of a rat kidney of group III displaying proximal convoluted tubular cells that show $(\mathrm{N} 1)$ : rounded heterochtomatic nucleus with an intact nuclear envelope (arrowhead), and a heterochtomatic nucleus (N2) with an indented nuclear envelop (arrowhead), abundan parallel electron dense mitochondria $(\mathrm{m})$ and irregularly cut apical microvilli (Mv) (EM X 7100).

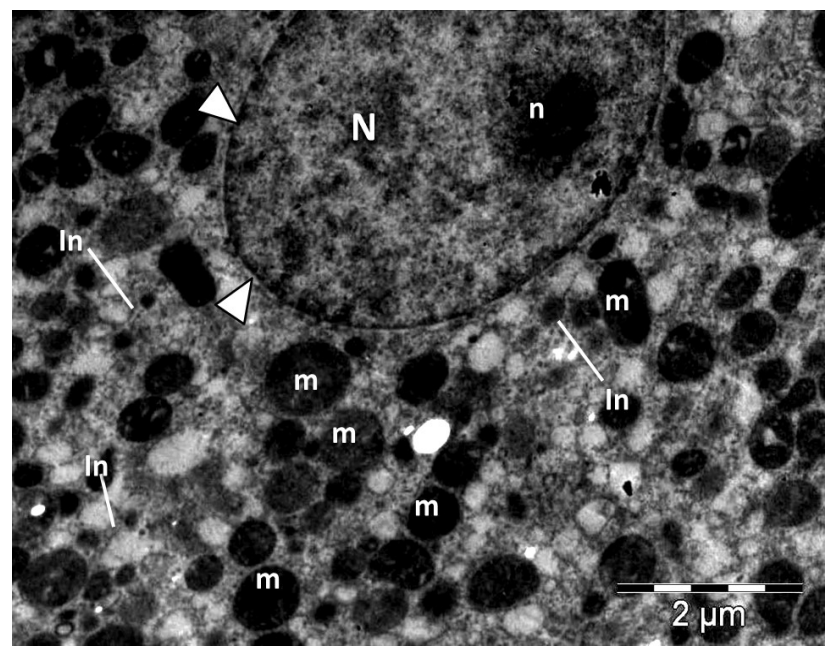

Fig. 15: An electron micrograph of a rat kidney of group III showing the cells of proximal convoluted tubules with heterochtomatic rounded nucleus (N) with a prominent nucleolus (n) and more or less intact nuclear envelop (arrowhead), scattered electron dense parallel mitochondria $(\mathrm{m})$ with apparently intact cristae. Apparently intact basal infoldings (In) can also be noticed. (EM X 5600)

Table 1: A table demonstrating mean values of blood urea nitrogen (BUN) among different study groups.

\begin{tabular}{lcccccc}
\hline & \multicolumn{2}{c}{ Group I (Control) } & \multicolumn{2}{c}{ Group II } & \multicolumn{2}{c}{ Group III } \\
\cline { 2 - 7 } & Mean & SD & Mean & SD & Mean & SD \\
\hline BUN & 19.18 & 3.76 & 76.65 & 9.96 & 33.48 & 4.79 \\
$P$-values & & & & & & \\
G I vs. G II & & $<0.0001$ (S) & & & \\
G II vs. G III & & & & $<0.0001$ & $(\mathrm{~S})$ & \\
G I vs. G III & & & & & 0.015 (S) \\
\hline
\end{tabular}

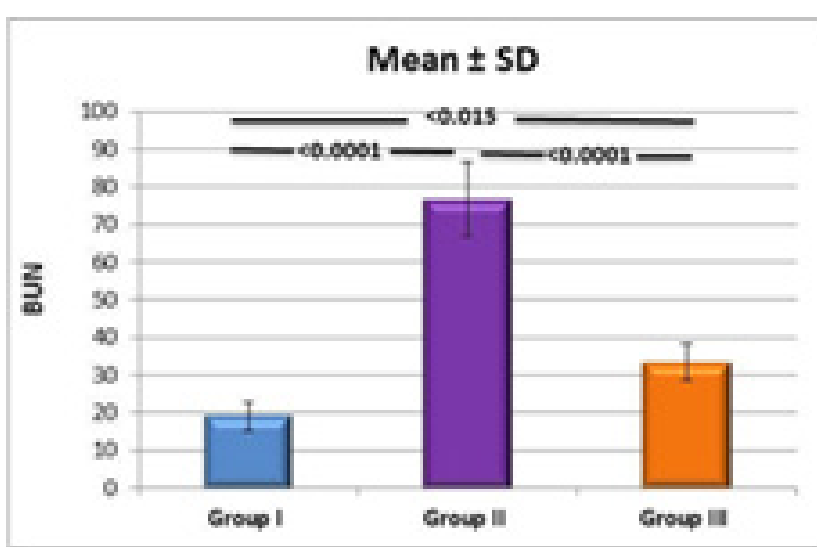

Histogram 1: illustrating mean values of blood urea nitrogen (BUN) obtained from the different groups of the examined animals.

Table 2: A table demonstrating mean values of serum creatinine levels among different study groups.

\begin{tabular}{lcccccc}
\hline & \multicolumn{2}{c}{ Group I (Control) } & \multicolumn{2}{c}{ Group II } & \multicolumn{2}{c}{ Group III } \\
\cline { 2 - 7 } & Mean & SD & Mean & SD & Mean & SD \\
\hline S. creatinine & 1.01 & 0.14 & 5.37 & 1.53 & 1.95 & 0.63 \\
$P$-values & & & & & & \\
G I vs. G II & & $<0.0001$ (S) & & & \\
G II vs. G III & & & & $<0.0001$ & (S) \\
G I vs. G III & & & & \multicolumn{2}{c}{0.301 (NS) } \\
\hline
\end{tabular}

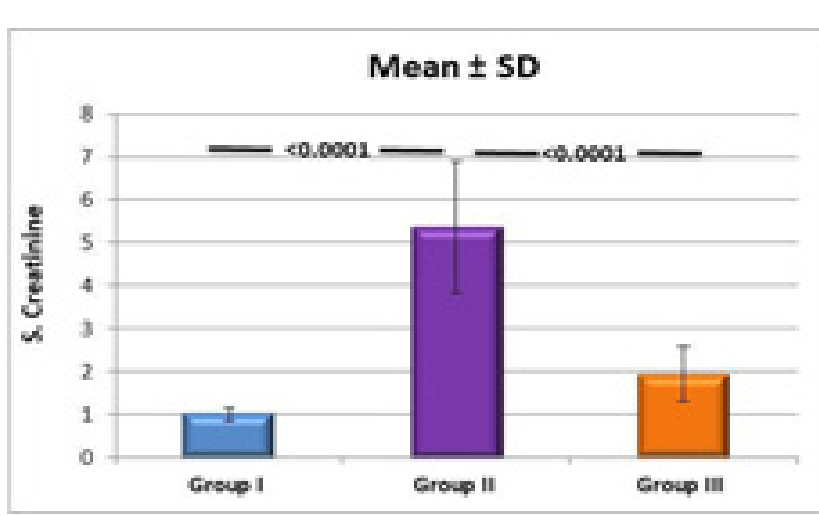

Histogram 2: illustrating mean values of serum creatinine levels obtained from the different groups of the examined animals.

Table 3: A table demonstrating mean values of renal matrix metalloproteinase 9 (MMP9) among different study groups.

\begin{tabular}{lcccccc}
\hline & \multicolumn{2}{c}{ Group I (Control) } & \multicolumn{2}{c}{ Group II } & \multicolumn{2}{c}{ Group III } \\
\cline { 2 - 7 } & Mean & SD & Mean & SD & Mean & SD \\
\hline MMP 9 & 0.25 & 0.10 & 2.11 & 0.53 & 0.88 & 0.09 \\
$P$-values & & & & & & \\
G I vs. G II & & $<0.0001$ (S) & & & \\
G II vs. G III & & & & $<0.0001$ (S) & \\
G I vs. G III & & & & & 0.020 (S) \\
\hline
\end{tabular}




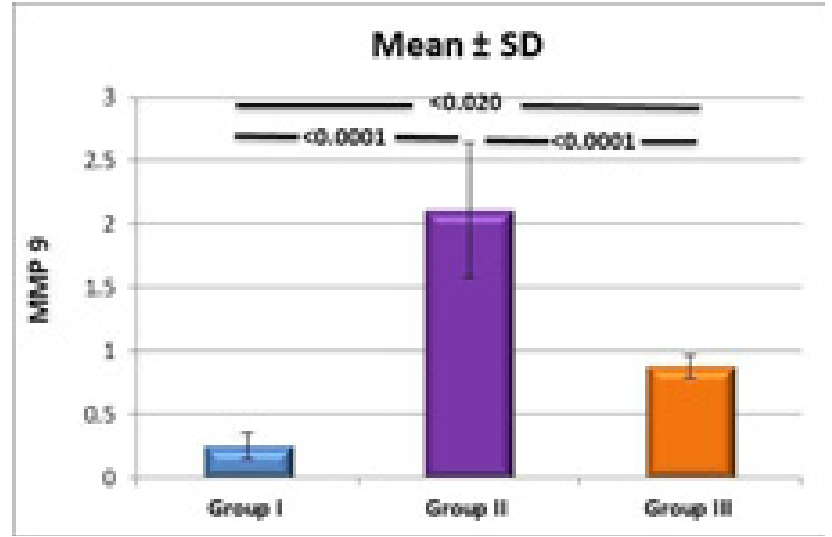

Histogram 3: illustrating mean values of renal matrix metalloproteinase 9 (MMP9) obtained from the different groups of the examined animals.

\section{DISCUSSION}

In the present work gentamicin administration resulted in proximal convoluted tubular cell necrosis, lost apical brush border, lost basal infoldings, ballooned mitochondria with damaged cristae, markedly increased levels of blood urea nitrogen, serum creatinine and renal tissue MMP9. This was in agreement with Nitescu et al., ${ }^{[20]}$ and Servais et al., ${ }^{[21]}$ who reported that gentamicin -induced tubular cell damage is mediated through reactive oxygen species (ROS) and this drug is an iron chelating agent that enhance iron-mediated lipid peroxidation. They added that stimulation of cell necrosis is an important cytotoxic mechanism of gentamicin in mesangial cells of proximal convoluted tubules. In the current work, gentamicin administration resulted in marked elevation of serum creatinine and blood urea nitrogen, levels. Similar results were detected by Romero et al., ${ }^{[22]}$ who observed sudden deterioration of renal functions following nine days of gentamicin administration in their study on male albino rats.

In order to to perform a normal function of proximal tubule and to avoid their cell death, their cells need proper adhesion to the basement membrane. To re-perform the physiological functions after cell injury, it is necessary to maintain the interactions of collagen IV-integrin. The matrix metalloproteases (MMPs) are responsible for regulation of collagen integrin interactions. MMP-9 is one of these materials that can damage types IV and V collagens, elastin, aggrecan, and gelatins. MMP9 mediate acute kidney injury due to different agents in glomeruli and tubular epithelial cells $^{[23,24,25]}$. Treatment with nebivolol markedly improved histological and biochemical deterioration exerted by gentamicin injection. This was in agreement with Broeders et al. ${ }^{[26]}$ who assumed that nebivolol exerts its vasodilator effect via endothelial b2-adrenoceptors binding, with a resultant increase in endothelial nitric oxide synthase and endothelial free calcium that play a fundamental role in oxygen supply and consumption regulation. They added that nebivolol produces stabilization of the lysosomal membranes with resultant decrease in lysosomal enzyme activities. Toprak et $a^{[27]}$ assumed that treatment with nebivolol for five days can decrease the formation of proteinaceous casts which developed as a result of dehydration and is effectively used in disorders associated with endothelial dysfunction. Pires et al, ${ }^{[10]}$ Akgullu et al, ${ }^{[28]}$ and Natasha et al,${ }^{[29]}$ demonstrated that nebivolol was effective in affording functional and structural protection via reduction in nitrotyrosine and hydrogen peroxide with a consequent decrease in NADPH dependent superoxide production and it was more efficient than atenolol as a nephroprotective drug in rats.

In conclusion our study showed that coadministration of nebivolol with gentamycine treatment could improve the renal histological and the biochemical deterioration exerted by gentamicin nephrotoxic effect in the adult male albino rats

\section{CONFLICT OF INTERESTS}

There are no conflicts of interest.

\section{REFERENCES}

1. Nagai, J. and Takano, M. (2004): Molecular aspects of renal handling of aminoglycosides and strategies for preventing the nephrotoxicity. Drug Metab. Pharmacokinet., 19: 159-170.

2. Rougier, F.; Claude, D.; Maurin, M. and Maire, P. (2004): Aminoglycoside nephrotoxicity. Curr. Drug Targets, 4 (2): 153-162.

3. Karadeniz, A.; Yildirim, A.; Simsek, N.; Kalkan, Y. and Celebi, F. (2008): Spirulina platensis protects against gentamicin-induced nephrotoxicity in rats. Phytother. Res., 22: 1506-1510.

4. Balakumar, P.; Rohilla, A. and Thangathirupathi, A. (2010): Gentamicin-induced nephrotoxicity: do we have a promising therapeutic approach to blunt it Pharmacol. Res., 62: 179-186.

5. Dursun, M.; Sahin, S.; Besiroglu, H.; Otunctemur, A.; Ozbek, E.; Cakir, S.S.; Cekmen, M. and Somay, A. (2018): Protective effect of nebivolol on gentamicin-induced nephrotoxicity in rats. Bratisl. Med. J., 119 (11): 718 - 725.

6. Ghaznavi, R. and Kadkhodaee, M. (2007): Comparative effects of selective and non-selective nitric oxide synthase inhibition in gentamicininduced rat nephrotoxicity. Arch Toxicol., 81: 453-457.

7. Banday, A.A.; Farooq, N.; Priyamvada, S.; Yusufi, A.N. and Khan, F. (2008): Time dependent effects of gentamicin on the enzymes of carbohydrate metabolism, brush border membrane and oxidative stress in rat kidney tissues. Life Sci., 82: 450-459.

8. Kone, B.C. (2004): Nitric oxide synthesis in the kidney: isoforms, biosynthesis and functions in health. Semin. Nephrol., 24: 299-315.

9. Dessy, C.; Saliez, J. and Ghisdal, P. (2005): Endothelial $\beta-3$ adrenoceptors mediate nitric oxidedependent vasorelaxation of coronary microvessels in response to the third-generation $\beta$-blocker nebivolol. Circulation, 112: 1198-1205. 
10. Pires, M. J.; Rodríguez-Peña, A.B.; Arévalo, M.; Cenador, B;. Evangelista, S,; Esteller, A.; SánchezRodríguez, A.; Colaço, A. and López-Novoa, J.M. (2007): Long-term nebivolol administration reduces renal fibrosis and prevents endothelial dysfunction in rats with hypertension induced by renal mass reduction. J. Hypertens., 25(12): 2486-2496.

11. Gupta, S. and Wright, H.M. (2008): Nebivolol: a highly selective beta1-adrenergic receptor blocker that causes vasodilation by increasing nitric oxide. Cardiovasc. Ther., 26: 189-202.

12. Maffei, A. and Lembo, G. (2009): Nitric oxide mechanisms of nebivolol. Ther. Adv. Cardiovasc. Dis., 3: 317-327.

13. Institutional Animal Care and Use Committee (IACUC), Office of Research Compliance (ORS) (2013) https://rsearch.iu.edu/doc/compliance/ animal-care/bloominton/iub-biacuc-nonpharmaceutical-and-pharmaceutical-gradecompounds-in-research animals.pdf.

14. Tobacco A, Meiattini F, Moda E, Tarii P. Simplified enzymic/colorimetric serum urea nitrogen determination. Clin. Chem.1979; 25:336 -7.

15. Fabiny DL, Ertingshausen G. Automated reaction-rate method fordetermination of serum creatinine with the Centrifichem. Clin. Chem. 1971; 17: $696-700$.

16. Bancroft JD and Gamble M: Connective tissue stains. Theory and Practice of Histological Techniques. J. Bancroft, editor. Churchill-Livingston Elsevier, London. 2008; 135-60

17. Graham L, Orenstein JM. Processing tissue and cells for transmission electron microscopy in diagnostic pathology and research. Nature protocols. 2007; 2(10): 2439-50.

18. Bengatta, S.; Arnould, C.; Letavernier, E.; Monge, M.; de Preneuf, H.M.; Werb, Z.; Ronco, P. and Lelongt, B. (2009):MMP9 and SCF Protect from Apoptosis in Acute Kidney Injury. Am. Soc. Nephrol., 20: 787-797.

19. Schmittgen, T. D., \& Livak, K. J. (2008). Analyzing real-time PCR data by the comparative $\mathrm{C}$ T method. Nature protocols, 3(6), 1101.

20. Nitescu, N.; Ricksten, S.E.; Marcussen, N.; Haraldsson, B.; Nilsson, U.; Basu, S. and Guron, G. (2006): N Acetylcysteine attenuates kidney injury in rats subjected to renal ischaemia-reperfusion. Nephrol. Dial. Transplant., 21:1240-1247.
21. Servais, H.; Jossin, Y.; Van Bambeke, F.; Tulkens, P.M. and Mingeot-Leclercq, M.P. (2006): Gentamicin causes apoptosis at low concentrations in renal LLC-PK1 cells subjected to electroporation. Antimicrob. Agents. Chemother., 50(4):1213-1221.

22. Romero, F.; Mariela, P.; Maribel, C.; Parra, G. and Durante, P. (2009): Effect of Uric Acid on Gentamicin-Induced Nephrotoxicity in Rats- Role of Matrix Metalloproteinases 2 and 9. Basic \& Clinical Pharmacology and Toxicology, 105: 416-424.

23. Lelongt, B.; Legallicier, B.; Piedagnel, R. and Ronco, P. (2001): Do matrix metalloproteinases MMP-2 and MMP-9 (gelatinases) play a role in renal development, physiology and glomerular diseases? Curr. Opin. Nephrol. Hypertens., 10:7-12.

24. Nony, P. and Schnelmann, R. (2003): Mechanisms of renal cell repair and regeneration after acute renal failure. J. Pharmacol. Exp. Ther., 304:905-912.

25. Catania, J.; Chen, G. and Parrish, A. (2007): Role of matrix metalloproteinases in renal pathophysiologies. Am. J. Physiol. Renal Physiol., 292: 905-911.

26. Broeders, M.A.; Doevendans, P.A.; Bekkers, B.C.; Bronsaer, R., Van Gorsel, E.; Heemskerk, J.W.; Egbrink, M.G.;Van Breda, E., ;Reneman, R.S. and Van Der, R. (2000): Nebivolol: a third-generation beta-blocker that augments vascular nitric oxide release: endothelial beta (2)-adrenergic receptormediated nitric oxide production. Circulation, 102: $677-684$.

27. Toprak, O.; Cirit, M.; Tanrisev, M.; Yazici, C.; Canoz, O.; Sipahioglu, M.; Uzum, A. ; Ersoy, R. and Sozmen, E.Y. (2008) : Preventive effect of nebivolol on contrast-induced nephropathy in rats. Nephrol. Dial. Transplant., 23 (3): 853-859.

28. Akgullu, C. M.; Huyut, A.; Boyacioglu, M.; Guleş, O,; Eryilmaz, U.; Hekim,T.; Dogan, E; Zencir, C. and Güngör, H. (2015): Nebivolol to attenuate the effects of hyper-homocysteinaemia in rats. Atherosclerosis, 240 (1):33-39.

29. Natasha, C. M., Tsarova, T.; Sasser, J.M. and Baylis, C. (2012): Protective actions of nebivolol on chronic nitric oxide synthase inhibition-induced hypertension and chronic kidney disease in the rat: a comparison with angiotensin II receptor blockade. Nephrol. Dial. Transplant., 27(3): 913-920. 
الملخص العربى

دراسة هستولوجية وكيميائية حيوية عن التأثثير الوقائي المحتمل للنيبيفولول علي السميه الكلويه المستحثه بالجينتامايسين في ذكور الجرذان البيضهاء البالغئه

شرين السيد توفيق ‘' ولمياء علي عبد السلامّ",

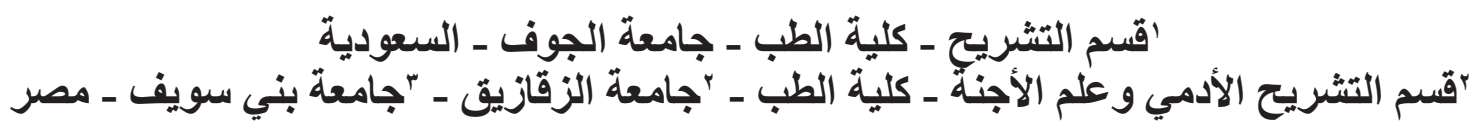

مقدمه: جنتاميسين مضاد حيوي قوي يستخدم على نطاق و اسع في القضاء بفاعليه علي البكتيريا السالبه الجر ام. الفتشل

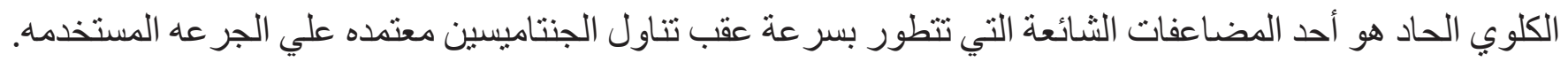

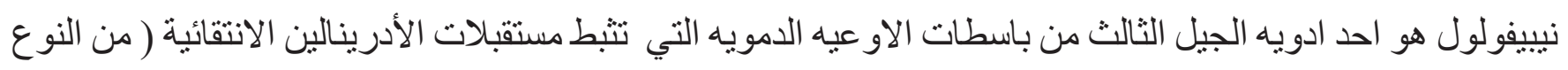

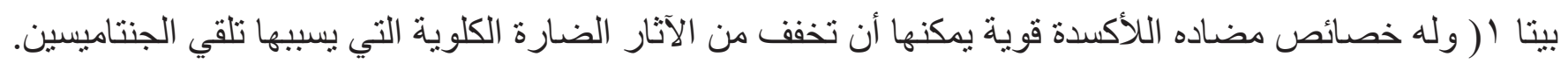

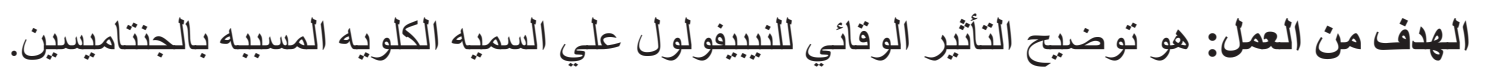

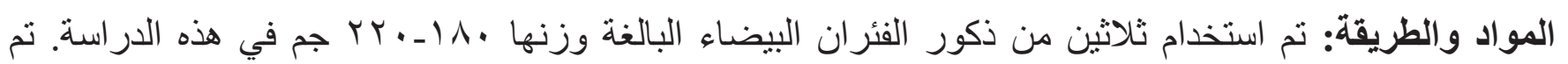

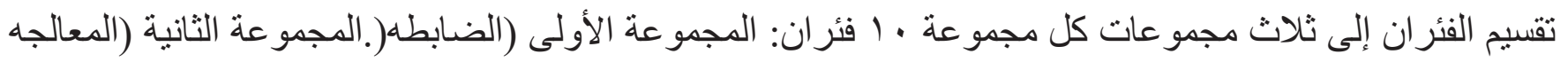

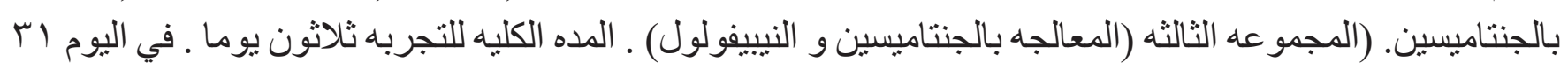

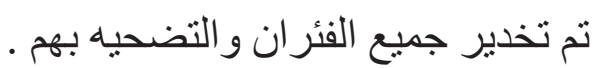

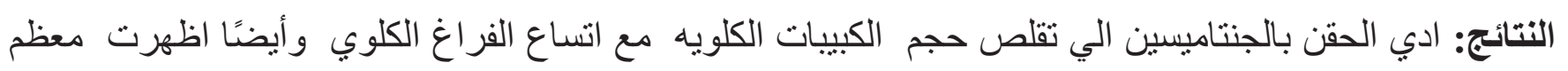

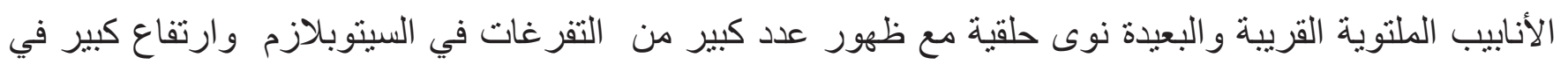

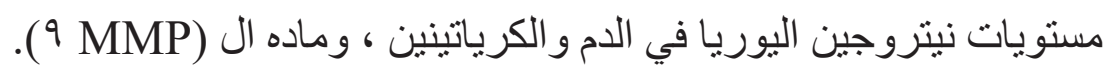

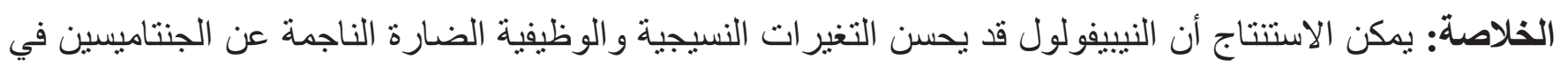
كلية ذكور الجرذان البيضاء البالغة. 